\title{
Fluticasone and salmeterol downregulate in vitro, fibroblast proliferation and ICAM-1 or H-CAM expression
}

\author{
M. Silvestri*, L. Fregonese*, F. Sabatini*, G. Dasic ${ }^{\#}$, G.A. Rossi*
}

Fluticasone and salmeterol downregulate in vitro, fibroblast proliferation and ICAM-1 or H-CAM expression. M. Silvestri, L. Fregonese, F. Sabatini, G. Dasic, G. A. Rossi. (C) ERS Journals Ltd 2001.

ABSTRACT: $\boldsymbol{\beta}_{2}$-adrenoreceptor agonists have pharmacological properties that may suggest an inhibitory effect on various aspects of the inflammatory and repair processes that characterize asthma.

Since fibroblasts express $\beta_{2}$-adrenoreceptors, the effects of different concentrations $(0.1-100 \mathrm{nM})$ of fluticasone propionate (FP), salmeterol (S) and their combination $(\mathrm{FP}+\mathrm{S})$ on lung fibroblast proliferation and adhesion molecule expression were evaluated.

Stimulation of human foetal lung fibroblasts with a fibrogenic cytokine, basic fibroblast growth factor (bFGF), resulted in a [methyl- $\left.{ }^{3} \mathrm{H}\right]$ thymidine $\left(\left[{ }^{3} \mathrm{H}\right] \mathrm{TdR}\right)$ uptake, four-fold higher than that of control cultures $(p=0.0001)$ and was significantly inhibited by $S$, at all the concentrations tested $(0.1-100 \mathrm{nM} ; p<0.05)$. No changes in bFGFinduced cell proliferation were observed in the presence of $\mathrm{FP}(0.1-100 \mathrm{nM} ; \mathrm{p}>0.05$, all comparisons). In addition, the association $\mathrm{FP}+\mathrm{S}$ did not improve the inhibitory activity of $S$ alone ( $>0.05$, each comparison). An upregulation of intercellular adhesion molecule-1 (ICAM-1) expression was induced by tumour necrosis factor- $\alpha$ $($ TNF- $\alpha)(p=0.0004)$, but not by interleukin-4 (IL-4) $(p>0.05)$, while none of the two cytokines were able to increase hyaluronic-cellular adhesion molecule (H-CAM) expression by lung fibroblasts $(p>0.05)$. A significant downregulation of ICAM-1 or H-CAM expression was demonstrated in the presence of FP or $\mathrm{S}$, at all concentrations tested (0.1-100 $\mathrm{nM} ; \mathrm{p}<0.01$, each comparison). Interestingly, $\mathrm{S}(10 \mathrm{nM}$ and $100 \mathrm{nM})$ was able to enhance the inhibitory activity of FP on ICAM-1 expression $(p<0.01)$, but not on H-CAM expression ( $p>0.1)$.

These results show that in human foetal lung fibroblasts, fluticasone propionate and salmeterol are effective in modulating in vitro, different lung fibroblast biological functions that are likely to be involved in airway remodelling. Eur Respir J 2001; 18: 139-145.
*Pulmonary Division, G. Gaslini Institute, Genoa, and " GlaxoWellcome S.p.A., Verona, Italy.

Correspondence: G.A. Rossi

Dept. of Pulmonary Diseases

G. Gaslini Institute

Largo G. Gaslini 5

16147 Genoa

Italy

Fax: 390103776590

Keywords: Airway remodelling

$\beta_{2}$-agonists

bronchial asthma

corticosteroids

Received: July 272000

Accepted after revision March 62001
Bronchial asthma is a chronic inflammatory disorder of the airways associated with reversible airway obstruction and bronchial hyperreactivity to a variety of stimuli [1]. Although each of these components is recognized as an important part of the asthmatic phenotype, the primary underlying abnormality is thought to be the chronic airway inflammation that gives rise to reversible obstruction, hyperresponsiveness and tissue remodelling [2].

The pathological findings of asthma include not only infiltration of mononuclear cells, mast cells and eosinophils in the airway tissues, but also subbasement membrane fibrosis [3]. Indeed, even in mild asthma, the inflammatory cells recruited in the airways release products that are able to mediate changes in airway patency and responsiveness [2], to damage bronchial epithelium and to stimulate myofibroblast proliferation and collagen depositing below the epithelial basement membrane [4]. As a consequence, two distinct processes can be observed: 1) regeneration ad integrum, leaving no residual trace of the previous injury; or 2) replacement by connective tissue, through the depositing of increased amounts of collagen (especially types III and V), polysaccharides (such as hyaluronic acid) and fibronectin by activated interstitial fibroblasts $[2,5,6]$.

Besides being modulated by a variety of cytokines and mediators released by airway inflammatory and parenchymal cells, fibroblasts may also interact directly with inflammatory cells, as demonstrated by the frequent observation of membrane apposition of eosinophils and myofibroblasts in the bronchial mucosa of asthmatic patients [4,6-8]. This close contact that is probably due to adhesion molecule expression on the interacting cell surface, may allow the stimulation of inflammatory cells by both direct cell-to-cell interaction and high cytokine concentrations [7].

Fibroblasts express a variety of surface molecules that include intercellular adhesion molecule-1 (ICAM1, CD54) and hyaluronic-cellular adhesion molecule (H-CAM, CD44), which belongs to a family of transmembrane glycoproteins [7, 8]. During inflammation or experimental exposure to cytokines, adhesion 
molecule expression is upregulated on both airway parenchymal cells and polymorphonuclear leukocytes and appears to be deeply involved in leukocyte transmigration and activation [9]. Indeed, eosinophils have been shown to adhere to fibroblasts and to be activated through the binding of ICAM-1 to leukocyte integrin leukocyte function-associated antigen-1 (LFA-1, CD11a/CD18), which is expressed on the eosinophil surface $[8,10]$.

As a receptor for glycan hyaluronate, as well as for collagen and fibronectin [11], the CD44 transmembrane glycoprotein appears to be involved in regulation of cell locomotion and modulation of cell-to-cell and cell-to-matrix interactions that occur during fibrogenesis $[8,12]$.

Since asthma is characterized by airway inflammation and reversible bronchial obstruction, it is treated with anti-inflammatory drugs (i.e. corticosteroids) and bronchodilators, such as $\beta_{2}$-adrenoreceptor agonists [1]. The therapeutic activity of corticosteroids results, at least in part, from inhibition of inflammatory mediator synthesis, release by parenchymal and inflammatory cells, and prevention of some of the histological changes that characterize airway remodelling in asthma, including subendothelial fibrosis $[1,13]$.

Similarly, it has been recently shown that $\beta_{2^{-}}$ adrenoreceptor agonists have in vivo and in vitro pharmacological properties suggesting an inhibitory effect on various aspects of the inflammatory response related to asthma [14].

With this background, a study was designed to evaluate in vitro, the activity of an inhaled glucocorticoid (fluticasone propionate (FP)) and of a longacting $\beta_{2}$-adrenoreceptor agonist (salmeterol xinafoate (S)) on fibroblast proliferation and adhesion molecule expression.

\section{Material and methods}

\section{Fibroblast culture}

GM 06114, a human foetal lung fibroblast cell line, was used in all the experiments performed. The GM 06114 cell line was selected because, in preliminary sets of experiments, it reacted to cytokine stimulation in a similar manner to human lung fibroblast primary cultures [7, 15]. Fibroblasts were cultured until confluence, then collected and spread into 96-well plates $\left(7,000 \mathrm{cells}^{\cdot} \mathrm{well}^{-1}\right)$ or into 24 -well plates $\left(60,000\right.$ cells $^{2}$ well $\left.{ }^{-1}\right)$ for the evaluation of adhesion molecule expression. The cells were incubated with Dulbecco's Modified Eagle Medium (DMEM) (Euroclone Ltd, Paignton, Devon, UK) supplemented with $20 \%$ foetal calf serum (FCS; Euroclone Ltd) and penicillin/streptomycin $\left(5,000 \mathrm{IU} \cdot \mathrm{mL}^{-1}\right)$ (ICN Biomedicals srl, Costa Mesa, CA, USA) for $24 \mathrm{~h}$ at $37^{\circ} \mathrm{C}$ in $5 \%$ carbon dioxide $\left(\mathrm{CO}_{2}\right)$. The medium was then removed and the cells resuspended in serum-free DMEM and incubated for an additional $48 \mathrm{~h}$. The medium was then removed and replaced with fresh serum-free DMEM, in the presence of different concentrations of different stimuli: basic fibroblast growth factor (bFGF, $0.5-100 \mathrm{ng} \cdot \mathrm{mL}^{-1}$ ) (SIGMA,
Saint Louis, Missouri, USA), tumour necrosis factor$\alpha$ (TNF- $\left.\alpha, 0.5-20 \mathrm{ng} \cdot \mathrm{mL}^{-1}\right)$ (Euroclone Ltd) or interleukin-4 (IL-4, $0.5-20 \mathrm{ng} \cdot \mathrm{mL}^{-1}$ ) (PeproTech EC Ltd, London, England). Unstimulated cells were used as negative control. After $24 \mathrm{~h}$-incubation, cell proliferation and molecule adhesion expression were evaluated as described later.

\section{Cell proliferation assay}

Deoxyribonucleic acid (DNA) synthesis was evaluated as incorporation of tritiated thymidine ([methyl- $\left.{ }^{3} \mathrm{H}\right]$ thymidine $\left(\left[{ }^{3} \mathrm{H}\right] \mathrm{TdR}\right)$ ) (Amerhsam International, Little Chalfont, Buckinghamshire, England). In preliminary experiments, cells were stimulated for $24 \mathrm{~h}$ with bFGF, TNF- $\alpha$, or IL-4 at concentrations ranging $0.5-20 \mathrm{ng} \cdot \mathrm{mL}^{-1}$, in order to determine which stimulus was most effective in inducing fibroblast proliferation. In the second set of experiments, the cells were stimulated for $24 \mathrm{~h}$ with bFGF at a final concentration of $5 \mathrm{ng} \cdot \mathrm{mL}^{-1}$, plus FP or $\mathrm{S}$, or plus the combination of the two drugs at concentrations ranging $0.1 \mathrm{nM}-100 \mathrm{nM}$. Unstimulated fibroblasts were used as negative control, while cells stimulated with bFGF alone were used as positive control. $\left.{ }^{3} \mathrm{H}\right] \mathrm{TdR}\left(0.1 \mathrm{microCi}^{\circ} \mathrm{well}^{-1}\right)$ was then added and, $18 \mathrm{~h}$ later, the cells were frozen and kept at $-20^{\circ} \mathrm{C}$ for $\geqslant 24 \mathrm{~h}$. After thawing, cells were collected on filter paper discs with an automatic cell harvester, the filters dissolved in $3 \mathrm{~mL}$ of scintillation fluid (ICN Biomedicals srl) in polypropylene vials and $\left[{ }^{3} \mathrm{H}\right] \mathrm{TdR}$ incorporation was measured using a liquid scintillation counter [16]. Incorporation was expressed as count $\cdot \min ^{-1}(\mathrm{cpm})$. Each experiment was carried out in triplicate. Cell viability was evaluated by Trypan blue dye exclusion test (Euroclone Ltd) after 24-h stimulation [16].

\section{Evaluation of adhesion molecule expression by human} foetal lung fibroblast

Cells grown into 24-well plates and stimulated with TNF- $\alpha$ or IL- 4 were trypsinized, collected, washed twice in DMEM, resuspended in DMEM plus 2\% FCS and $0.1 \%$ sodium azide in $\mathrm{NaCl} 0.9 \%$, and stained with monoclonal antibodies to evaluate adhesion molecule expression. Cell viability was evaluated by Trypan blue dye exclusion test. To evaluate the expression of ICAM-1 and H-CAM, $100 \mu \mathrm{L} \cdot$ well $^{-1}$ of the cell suspensions were placed into round-bottomed microtiter 96-well plates. After incubation for $30 \mathrm{~min}$ at $4{ }^{\circ} \mathrm{C}$ with fluorescein isothiocyanate (FITC)-conjugated monoclonal antibodies (MAB), antihuman (ah)-ICAM-1 (CD54) (Biosource International Inc., Camarillo, CA, USA) or antihuman (ah)-H-CAM (CD44) (Caltag Laboratories, Burlingame, CA, USA), the cells were washed twice and then fixed with $0.5 \%$ paraformaldehyde and analysed by immunofluorescence flow cytometry (Becton Dickinson Immunocytometry Systems; Mountain View, CA, USA). To compare the fluorescence intensities of different samples from the same 
experiments, identical settings of the logarithmic amplifier were used and listmode files were analysed with CELLQuest software (Becton Dickinson). After conversion to linear fluorescence intensity units to obtain a linear function of fluorescence intensity over a wide range, the average background linear fluorescence obtained with the control antibody, the antihuman (ah)-CD3 FITC (Becton Dickinson), was subtracted from the average fluorescence intensity of the specifically stained cells. The possible changes in cell size in the different conditions were controlled by forward light scatter signal of the flow cytometer, proportional to cell size and algebraically adjusting to increases in cell surface area so that intensity in relative linear fluorescence units could be obtained. This adjustment permits the correlation of the average fluorescence intensity with the cell surface density of the stained antigens. All experiments were performed in triplicate. The intensity of fluorescence was expressed as mean fluorescence channel ( $\mathrm{mfc})$ [17].

To evaluate the effect of FP and/or $\mathrm{S}$ on adhesion molecule expression, fibroblasts were stimulated for $24 \mathrm{~h}$ with TNF- $\alpha$ or IL-4 in the presence of different concentrations of FP, S or the association of the two drugs $(0.1-100 \mathrm{nM})$. Evaluation of ICAM-1 and H-CAM was performed as described above. Cell viability was evaluated by Trypan blue dye exclusion test.

\section{Data and statistical analysis}

Mann-Whitney U-test or paired t-test were used to compare data, when appropriate. Data parametrically distributed are presented as arithmetic mean \pm SEM. A p-value $<0.05$ was set to indicate the level of statistically significant differences.

\section{Results}

Fibroblast proliferation and adhesion molecule expression following stimulation with basic fibroblast growth factor, tumour necrosis factor- $\alpha$ or interleukin-4

Among the stimuli tested, bFGF was highly effective in inducing a dose-dependent lung fibroblast proliferation, statistically significant at all the concentrations tested $(p<0.01$, each comparison with control cultures; fig. 1). In contrast, no significant increase in lung fibroblast proliferation was observed when the cells were stimulated with IL-4 or TNF- $\alpha$ ( $p>0.05$, each comparison; fig. 1).

Unstimulated fibroblasts grown in DMEM medium showed negligible basal expression of ICAM-1 but elevated levels of H-CAM (fig. 2). TNF- $\alpha\left(5 \mathrm{ng} \cdot \mathrm{mL}^{-1}\right)$ was able to induce an upregulation of ICAM-1 expression by lung fibroblasts (control: $6.88+0.44$ $\left.\mathrm{mfc} ; \mathrm{TNF}-\alpha 5 \mathrm{ng} \cdot \mathrm{mL}^{-1}: 21.47 \pm 2.44 \mathrm{mfc} ; \mathrm{p}=0.0004\right)$ (fig. 2). This upregulation was not seen with IL-4 (fig. 2).

Neither TNF- $\alpha$ nor IL-4 were able to significantly increase the expression of H-CAM, probably because

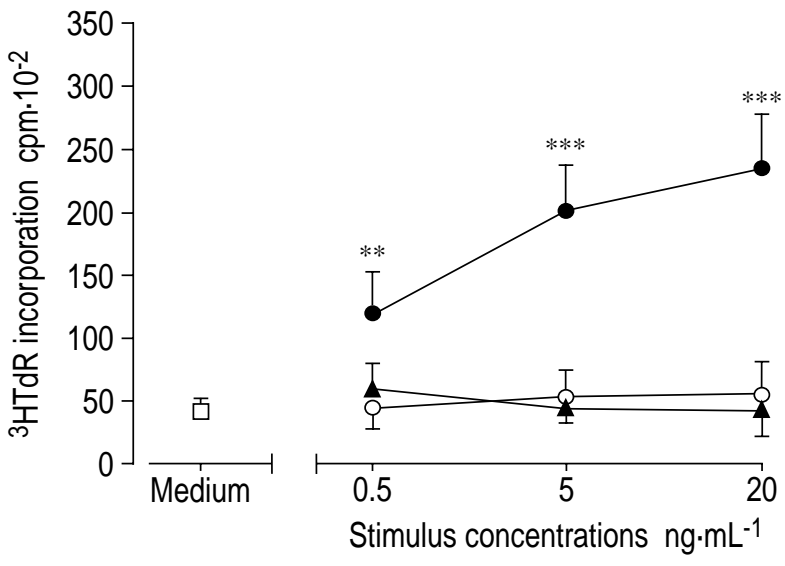

Fig. 1. - Effects of different stimuli on human foetal lung fibroblast cell line proliferation. The different culture conditions, i.e. unstimulated cells ( $\square$ ), cells stimulated with tumour necrosis factor- $\alpha(\mathrm{TNF}-\alpha)(\boldsymbol{\Delta})$, with interleukin (IL)-4 $(\bigcirc)$, or with basic fibroblast growth factor (bFGF) $(\mathbf{O})$, are plotted against tritiated thymidine $\left({ }^{3} \mathrm{HTdR}\right)$ cell proliferation evaluated as count $\cdot \mathrm{min}^{-1}$ $(\mathrm{cmp})$. Values are expressed as mean \pm SEM. $* *: \mathrm{p}<0.01 ; * * *$ : $\mathrm{p}<0.001$ versus unstimulated cells.

of its high basal expression (control: 129.71 \pm $5.60 \mathrm{mfc}$ ) (fig. 2).

Effect of fluticasone propionate andlor salmeterol on fibroblast proliferation

At all the concentrations tested, FP had no significant effect on bFGF-induced fibroblast proliferation (fig. 3). Conversely, at the same concentrations, $\mathrm{S}$ was highly effective in inhibiting fibroblast proliferation $(\mathrm{p}<0.01$, each comparison with $\mathrm{bFGF}$-stimulated cultures; fig. 3). While at the three highest concentrations tested, the inhibitory activity of $\mathrm{S}$ alone appeared to be higher compared to S plus FP, the levels of $\left.{ }^{3} \mathrm{H}\right] \mathrm{TdR}$ in the presence of $\mathrm{S}$ alone or of $\mathrm{S}+\mathrm{FP}$ were not statistically different $(\mathrm{p}>0.05$, each comparison; fig. 3).

Effects of fluticasone propionate andlor salmeterol on adhesion molecule expression

When evaluating changes in adhesion molecule expression induced by $\mathrm{FP}$ and $\mathrm{S}$, it was found that both drugs were able to significantly inhibit ICAM-1 and H-CAM expression on human lung fibroblast surface. Exposure to FP induced a dose-dependent downregulation of TNF- $\alpha$-stimulated ICAM-1 expression, significant at all the concentrations tested $(\mathrm{p}<0.001$, each comparison with TNF- $\alpha$-stimulated cultures; fig. 4). A significant downregulation of TNF$\alpha$-stimulated ICAM-1 expression was also induced by $\mathrm{S}$ at all the concentrations tested $(\mathrm{p}<0.01$, each comparison with TNF- $\alpha$-stimulated cultures). The inhibitory effect of $\mathrm{S}$ was lower than that observed in the presence of FP at the three highest concentrations tested ( $p<0.01$; fig. 4). Comparison between the effect of FP alone and of FP $+\mathrm{S}$ showed that $\mathrm{S}$ at the two highest concentrations (10 and $100 \mathrm{nM}$ ), added to 

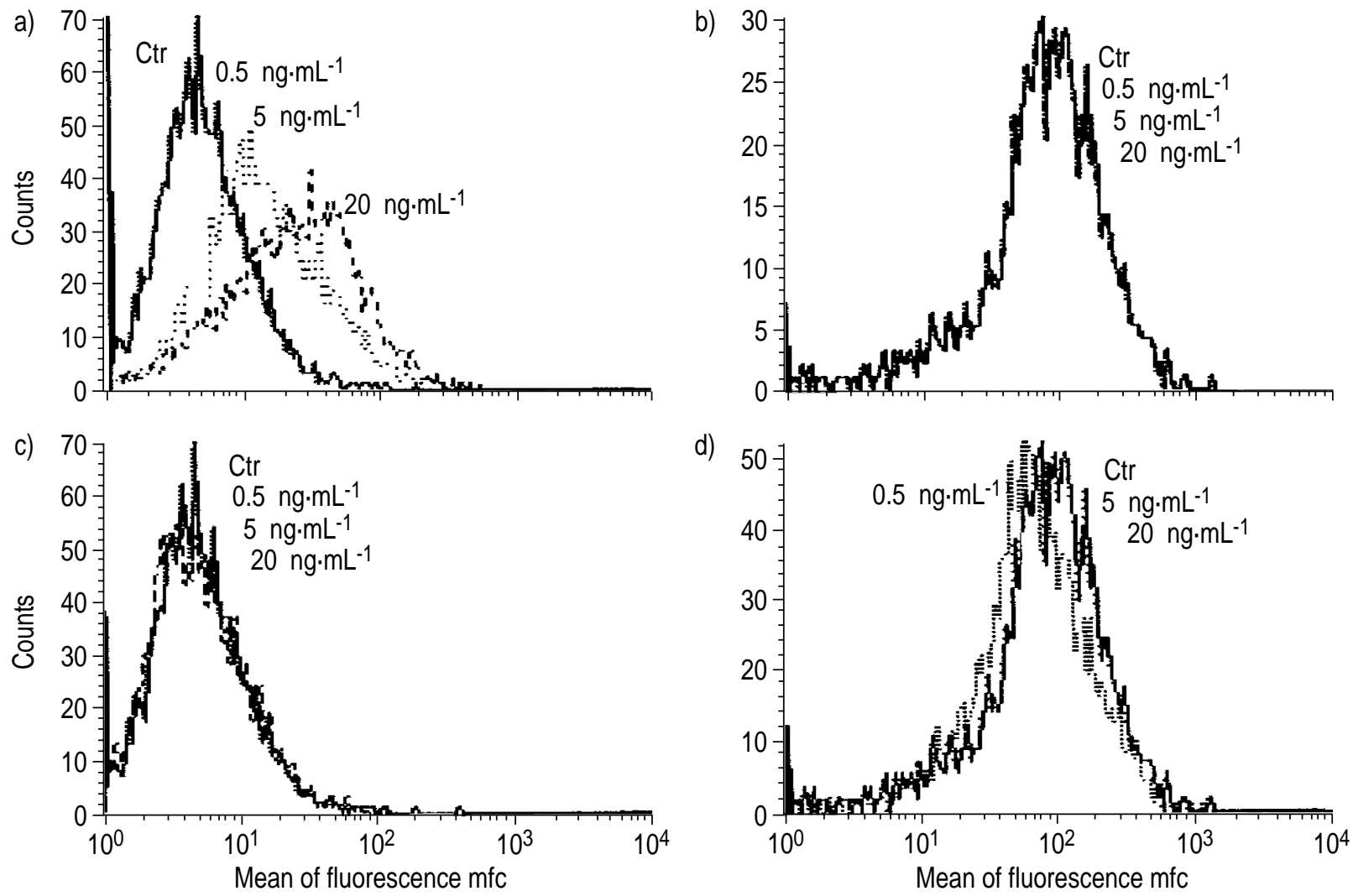

Fig. 2. - Intercellular adhesion molecule (ICAM)-1 (CD54) and hyaluronic cellular adhesion molecule (H-CAM, CD44) expression on the surface of a human foetal lung fibroblast cell line. Flow cytometry histograms of CD54 expression on fibroblasts stimulated with different concentrations $\left(0.5-20 \mathrm{ng} \cdot \mathrm{mL}^{-1}\right)$ of tumour necrosis factor- $\alpha(\mathrm{TNF}-\alpha)$ (a) or of interleukin (IL)-4 (c). Flow cytometry histograms of CD44 expression on fibroblasts stimulated with different concentrations of TNF- $\alpha$ (b) or of IL-4 (d). mfc: mean fluorescence channel; Ctr: control.

FP at the same concentrations, enhanced the inhibition induced by FP alone on ICAM-1 expression (FP $10 \mathrm{nM} 6.97 \pm 1.00 \mathrm{mfc}, \mathrm{FP}+\mathrm{S} 10 \mathrm{nM} 4.53 \pm 0.77 \mathrm{mfc}$,

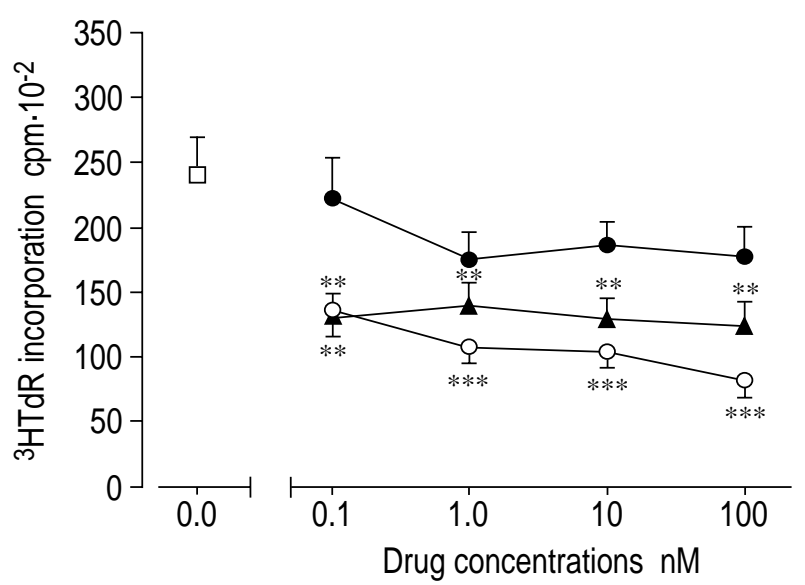

Fig. 3. - Effects of different concentrations of fluticasone propionate $(\bullet)$, salmeterol $(\bigcirc)$ or the association of the two drugs $(\boldsymbol{\Delta})$ on human foetal lung fibroblasts proliferation induced by basic fibroblast growth factor (bFGF). The different concentrations $(0.1-100 \mathrm{nM})$ of the drugs are plotted against tritiated thymidine $\left({ }^{3} \mathrm{HTdR}\right)$ fibroblast proliferation evaluated as counts $\cdot \mathrm{min}^{-1}$. Values are expressed as mean \pm SEM. $\square$ : unstimulated cells. $* *: p<0.01$; $* * *: \mathrm{p}<0.001$ versus bFGF-stimulated cell cultures without drugs. $\mathrm{p}=0.0058 ; \mathrm{FP} 100 \mathrm{nM} 5.19 \pm 0.84 \mathrm{mfc}, \mathrm{FP}+\mathrm{S} 100 \mathrm{nM}$ $4.63 \pm 1.37 \mathrm{mfc}, \mathrm{p}=0.008)$.

Since neither TNF- $\alpha$ nor IL-4 modified H-CAM expression, after the preliminary experiments the effect of the two drugs on this adhesion molecule was evaluated on unstimulated fibroblasts. Each concentration of FP or S alone significantly inhibited H-CAM expression (fig. 4). Particularly, FP tended to be stronger than $\mathrm{S}$ in inhibiting basal H-CAM expression, but these differences did not reach statistical significance $(p>0.1)$. In addition, $S$ did not significantly modify the inhibitory activity of FP ( $>0.1$; fig. 4). None of these effects induced by FP, $\mathrm{S}$, or the combination of the two drugs, was associated with a statistically significant modification of cell viability ( $p>0.1$, each comparison; data not shown).

\section{Discussion}

Evaluating in vitro, a human foetal lung fibroblast cell line, it has been shown that long-acting $\beta_{2}$-agonist $\mathrm{S}$ is highly effective in inhibiting fibroblast proliferation and ICAM-1 and CD44 surface molecule expression. While no changes in cell proliferation were observed in the presence of FP, this drug was more effective than $\mathrm{S}$ in downregulating ICAM-1 and CD44 expression. Finally, associated S significantly 


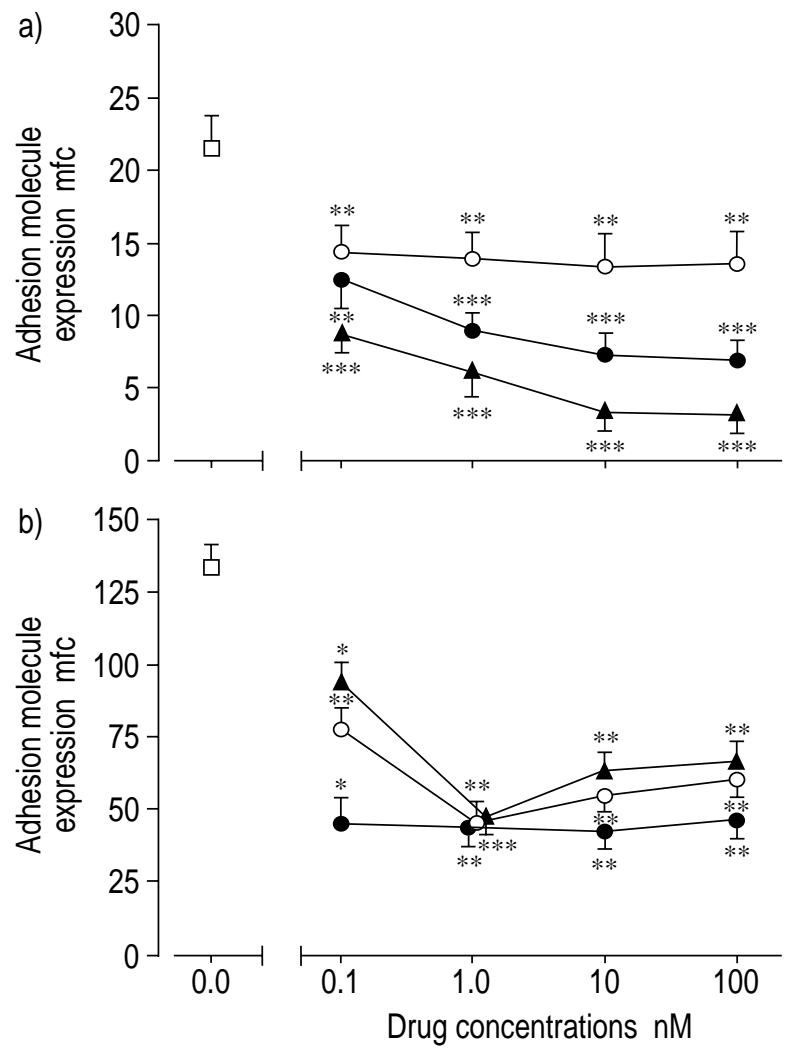

Fig. 4. - Effects of different concentrations of fluticasone propionate $(\bullet)$, salmeterol $(\bigcirc)$ or the association of the two drugs $(\boldsymbol{\Delta})$ on tumour necrosis factor- $\alpha(\mathrm{TNF}-\alpha)$ induced intracellular adhesion molecule (ICAM)-1 (CD54) expression (a) and on constitutive hyaluronic cellular adhesion molecules (H-CAM; CD44) expression (b) on surface of a human foetal lung fibroblast cell line. The different concentrations $(0.1-100 \mathrm{nM})$ of the drugs are plotted against the mean fluorescence channel $(\mathrm{mfc})$. Values expressed as mean \pm SEM. $\square$ : unstimulated cells. *: $\mathrm{p}<0.05 ; * *$ : $\mathrm{p}<0.01 ; * * *: \mathrm{p}<0.001$ versus control cell cultures grown in the absence of drugs.

increased the inhibitory activity of FP alone on ICAM-1 expression.

Subepithelial layer thickening associated with an increased number of fibroblasts is characteristic of airway remodelling in asthma $[4,5,18-20]$. Evaluation of endobronchial biopsy specimens from asthmatics showed that the subepithelial layer consisted of dense fibrillary collagen types III and V of fibroblasts, rather than epithelial origin $[5,6]$. Although the effects of inflammatory processes on collagen deposits are still unclear, several inflammatory cell types, including mast cells, macrophages, eosinophils and epithelial cells, are able to produce and release factors that may stimulate fibroblasts [6].

In addition to secreting extracellular matrix components, fibroblasts are able to release a variety of inflammatory cytokines and chemokines [21, 22] and to express surface molecules, such as ICAM-1 [15] and CD44 [8, 9]. ICAM-1 acts as a ligand for surface molecules expressed on eosinophils, monocytes and lymphocytes [23]. The expression of ICAM-1 is increased in tissues with inflammatory reactions [24] and it is associated with leukocyte transmigration over fibroblasts [25] and with increased eosinophil adhesion and activation [10]. Therefore, an increased expression of ICAM-1 in response to cytokines may represent a mechanism by which fibroblasts adhere to and interact with inflammatory and immuno-effector cells in the respiratory mucosa of atopic patients $[10$, 23].

The CD44 transmembrane glycoprotein represents a receptor for the extracellular matrix components and is thought to be involved in modulation of cell-tocell and cell-to-matrix interaction that occurs during fibrogenesis $[8,12]$. In addition to providing mechanical support to the tissues, the extracellular matrix is increasingly recognized as a source of signals for cellular localization, migration, differentiation and activation $[12,26,27]$. Recent data indicate that CD44 may be related to fibroblast migration and pulmonary repair after injury. CD44 is the surface receptor for matrix proteins supporting cell motility, including fibronectin and hyaluronan [28], and its expression is increased in hypertrophic scar fibroblasts [29]. Interestingly, lung tissues from patients with acute alveolar fibrosis revealed CD44-expressing mesenchymal cells through newly formed fibrotic tissue and high concentrations of this surface protein were found along the motile structures (filopodia and lamellopodia) of fibroblasts [28].

The most surprising finding of the present study was that $\mathrm{S}$ was more effective than FP in inhibiting bFGFinduced fibroblast proliferation. $\beta_{2}$-adrenoceptor agonists interact with specific cell membrane receptors, which activate signal transduction mechanisms leading to cellular responses that may be different in different cell types [14]. Indeed, in addition to inhibiting or reversing the contractile response of bronchial smooth muscles, these compounds modulate a variety of inflammatory and immuno-effector cell functions, including T-lymphocyte proliferation and mononuclear cell surface receptor expression [14, $16,30]$. Using a human foetal lung fibroblast cell line, this study has shown that $\mathrm{S}$ was highly effective in downregulating fibroblast proliferation and in reducing the expression of adhesion molecules that are likely to be involved in airway remodelling. In addition, at the two highest concentrations tested, $\mathrm{S}$ significantly increased the inhibitory activity of FP alone on ICAM-1 expression. These findings are in agreement with the results of a recent report, showing inhibition of ICAM-1 expression by human lung fibroblast primary cultures in the presence of budesonide and formoterol [31]. Indeed, $\beta_{2}$-adrenergic receptor agonists may also activate glucocorticoid receptors in primary human lung fibroblasts [32].

Although more effective than $S$ in reducing surface molecule expression, FP did not have a direct inhibitory activity on bFGF-induced fibroblast proliferation. Glucocorticosteroids influence not only protein translation, but also post-transcriptional processing of protein synthesis [33]. The complexity of the mechanisms involved in glucocorticoid activities may explain why cellular responses to these drugs are not only highly dependent on cell types, but also on cell functions [33-35].

Clinical studies demonstrate that in asthma, lowdose inhaled corticosteroids are not only able to 
downregulate the intensity of bronchial inflammation, but also to decrease subepithelial layer thickness [6, 14]. Indeed, in vivo corticosteroids may be effective in controlling tissue remodelling by inhibiting several aspects of the inflammatory process, such as regulation of the transcription of genes related to the production of cytokines able to activate leukocytes and lung parenchymal cells $[5,6,31-33]$.

In summary, these data support at biological level the hypothesis that the combination of the two types of drugs, long-acting $\beta_{2}$-adrenoceptor agonists and inhaled steroids, not only allows a better clinical control of asthma, but may also help to prevent longterm deterioration of lung function [1]. Although the concentrations of drugs used in vitro in this paper are similar to those found in peripheral lung tissue after $50 \mu \mathrm{g}$ inhaled dose of salmeterol [35], the clinical importance of the experimental observations reported here deserves further investigation.

\section{References}

1. Guidelines for the diagnosis management of asthma: expert panel report 2. National Institutes of Health, National Heart, Lung and Blood Institutes. Publication Number 97-4051, 1997; 1-4.

2. Crimi E, Spanevello A, Neri M, Ind PW, Rossi GA, Brusasco V. Dissociation between airway inflammation and airway hyperresponsiveness in allergic asthma. Am J Respir Crit Care Med 1998; 157: 4-9.

3. Djukanovic RW, Roche W, Wilson JW, et al. Mucosal inflammation in asthma. Am Rev Respir Dis 1990; 142: $434-457$.

4. Brewster CEP, Howarth PH, Djukanovich R, Wilson J, Holgate ST, Roche WR. Myofibroblasts and subendothelial fibrosis in bronchial asthma. Am J Respir Cell Mol Biol 1990; 3: 507-511.

5. Roche WR, Beasley R, Williams JH, Holgate ST. Subepithelial fibrosis in bronchial asthma. Lancet 1989; i: $520-530$.

6. Roche WR. Fibroblasts and extracellular matrix in bronchial asthma. In: Busse $\mathrm{W}$, Holgate ST, eds. Asthma and rhinitis. Cambridge, MA, Blackwell Science Inc., 1995; pp. 554-562.

7. Doucet C, Brouty-Boyé D, Pottin-Clemenceau C, Jasmin C, Canonica GW, Azzarone B. IL-4 and IL-13 specifically increase adhesion molecule and inflammatory cytokine expression in human lung fibroblasts. Int Immunol 1998; 10: 1421 - 1433.

8. Kasper M, Gunther U, Dall P, Schuh D, Haroske G, Muller M. Distinct expression pattern of CD44 isoforms during human lung development and in pulmonary fibrosis. Am J Respir Cell Mol Biol 1995; 13: $648-656$.

9. Manolitsas ND, Trigg CJ, McAulay AE, et al. The expression of intercellular adhesion molecule-1 and the beta 1-integrins in asthma. Eur Respir $J$ 1994; 7: $1439-1444$

10. Takafuji S, Shoji S, Ito K, Yamamoto K, Nakagawa $\mathrm{T}$. Eosinophil degranulation in the presence of lung fibroblasts. Int Arch Allergy Immunol 1998; 117: 5254.

11. Lesley J, Hyman R, Kincade PW. CD44 and its interaction with extracellular matrix. Adv Immunol 1993; 54: $271-335$.
12. Roche WR. Fibroblasts and asthma. Clin Exp Allergy 1991; 21: $545-548$.

13. Olivieri D, Chetta A, del Donno M, et al. Effects of short term treatment with low dose inhaled fluticasone propionate on airway inflammation and remodelling in mild asthma: a placebo-controlled study. Am J Respir Crit Care Med 1997; 155: 1864 - 1871.

14. Barnes BJ. Beta-adrenergic receptors and their regulation. Am J Respir Crit Care Med 1995; 152: 828 860.

15. Spoelstra FM, Postma DS, Hovenga H, Noordhoek JA, Kauffman HF. Interferon- $\gamma$ and interleukin-4 differentially regulate ICAM-1 and VCAM-1 expression on human lung fibroblasts. Eur Respir J 1999; 14 : $759-766$.

16. Oddera S, Silvestri M, Scarso L, Testi R, Rossi GA. Salmeterol inhibits the allergen-induced mononuclear cell proliferation and downregulates GM-CSF release and HLA-DR expression by monocytes. Pulm Pharmacol 1997; 10: 43-49.

17. Rossi GA, Sacco O, Balbi B, et al. Human ciliated bronchial epithelial cells: expression of the HLA-DR antigens and of the HLA-DR alpha gene, modulation of the HLA-DR antigens by gamma interferon and antigen presenting function in the mixed leukocytes reaction. Am J Respir Cell Mol 1990; 3: 431-440.

18. Redington AE, Howarth PH. Airway remodelling in asthma. Thorax 1997; 52: 310-312.

19. Gizycki MJ, Ådelroth E, Rogeres AV, O'Byrne PM, Jeffery PK. Myofibroblast involvement in the allergeninduced late response in mild atopic asthma. Am J Respir Cell Mol Biol 1997; 16: 664-673.

20. Bousquet J, Jeffery PK, Busse WW, Johnson M, Vignola AM. Asthma: from bronchoconstriction to airway inflammation and remodelling. Am J Respir Crit Care Med 2000; 161: 1720-1745.

21. Tobler A, Meier R, Seitz M, Dewald B, Baggiolini M, Fey MF. Glucocorticoids downregulate gene expression of GM-CSF, NAP-1/IL-8, and IL-6, but not of M-CSF in human fibroblasts. Blood 1992; 79: 45-51.

22. Noso N, Sticherling M, Bartels J, Malet AL, Christophers E, Schroder JM. Identification of an Nterminally truncated form of the chemokine RANTES and granulocyte-macrophage colony stimulating factor as major eosinophil attractant released by cytokine-stimulated dermal fibroblasts. $J$ Immunol 1996; 156: 1946-1953.

23. Montefort S, Roche WR, Howarth $\mathrm{PH}$, et al. Intracellular adhesion molecule -1 (ICAM -1) and endothelial leukocyte adhesion molecule-1 (ELAM-1) expression in the bronchial mucosa of normal and asthmatic subjects. Eur Respir J 1992; 90: 1379-1385.

24. Tosi MF, Stark JM, Smith CW, Hamedani A, Gruenert DC, Infeld MD. Induction of ICAM-1 expression on human airway epithelial cells by inflammatory cytokines: effects on neutrophil-epithelial cells adhesion. Am J Respir Cell Mol Biol 1992; 7: $214-$ 221.

25. Tessier PA, Cattaruzzi P, McColl SR. Inhibition of lymphocyte adhesion to cytokine-activated synovial fibroblasts by glucocorticoids involves the attenuation of vascular cell adhesion molecule-1 and intercellular adhesion molecule-1 gene expression. Arthritis Rheum 1996; 39: 226-234.

26. Damsky CH, Werb Z. Signal transduction by integrin receptors for extracellular matrix: cooperative process- 
ing of extracellular information. Curr Opin Cell Biol 1992; 4: $772-781$

27. Yamaguchi Y, Mann DM, Ruoslahti E. Negative regulation of transforming growth factor- $\beta$ by the proteoglycan decorin. Nature 1989; 346: 281-284.

28. Svee K, White J, Vaillant $\mathrm{P}$, et al. Acute lung injury fibroblast migration and invasion of a fibrin matrix is mediated by CD44. J Clin Invest 1996; 98: 1713 - 1727.

29. Messadi DV, Bertolani CM. CD44 and hyaluronan expression in human cutaneous scar fibroblasts. $\mathrm{Am}$ $J$ Pathol 1993; 142: 1041 - 1049.

30. Oddera S, Silvestri M, Lantero S, Sacco O, Rossi GA. Downregulation of the expression of intercellular adhesion molecule (ICAM)-1 on bronchial epithelial cells by a beta2-adrenoceptor agonist: fenoterol. J Asthma 1998; 35: 401 - 408.

31. Spoelstra FM, Postma DS, Hovenga H, Noordhoek JA, Kauffman HF. Budesonide and formoterol inhibit
ICAM1 and VCAM-1 expression on human lung fibroblasts. Eur Respir J 2000; 15: 68 - 74 .

32. Eickelberg $\mathrm{O}$, Roth $\mathrm{M}$, Lörx R, et al. Ligandindependent activation of the glucocorticoid receptor by $\beta_{2}$-adrenergic receptor agonists in primary human lung fibroblasts and vascular smooth muscle cells. J Biol Chem 1999; 274: 1005-1010.

33. Barnes JP, Pedersen S. Efficacy and safety of inhaled corticosteroids in asthma. Am Rev Respir Dis 1993; 148: S1 - S26.

34. Mercier L, Thompson EB, Simons SS. Dissociation of steroid binding to receptors and steroid induction of biological activity in a glucocorticoid-responsive cell. Endocrinology 1983; 112: 601-607.

35. Johnson M. Mechanisms of action of $\beta_{2}$-adrenoceptor agonists. In: Busse $\mathrm{W}$, Holgate S. eds. Asthma \& Rhinitis, 2nd Ed, volume 2. Massachusetts, Blackwell Science, Inc., 2001, pp. $1278-1295$. 